\title{
Prologo al libro El Modelo de Gestión de la Investigación. Modelo I+D+i de la UNAN-Managua
}

\begin{abstract}
El libro titulado El Modelo de Gestión de la Investigación. Modelo I+D+i de la UNANManagua, fue presentado el miércoles 10 de junio del 2015 en la Biblioteca de la Facultad Regional Multidisciplinaria de Estelí (FAREM-Estelí) y la presentación estuvo a cargo de la MSc. Beverly Castillo Herrera, Docente y Coordinadora de Investigación e Innovación de la Facultad.
\end{abstract}

El Dr. Manuel Enrique Pedroza, autor de esta obra, durante muchos años se ha dedicado a promover la investigación desde diferentes espacios y localidades. Uno de sus más grandes retos ha sido que el investigador o investigadora disponga los resultados de su trabajo al servicio del pueblo, y que los aportes al conocimiento no queden en el anonimato, sino que sean aprovechados por todas aquellas personas que estén comprometidos con el desarrollo integral de nuestro país.

Este libro merece su lectura y análisis por cuanto el Modelo de Gestión de la Investigación, Modelo $I+D+i$ de la UNAN-Managua, constituye un aporte conceptual integral que va más allá de la teoría, por cuanto representa una imagen objetivo circular, dinámica, no lineal sino sistémica. Representa la visión prospectiva de los procesos de investigación de la UNAN-Managua, qué se desea hacer y cómo se propone lograrlo, desde la perspectiva de la investigación científica y los procesos de innovación, tecnológica, socio-productiva, organizacional y educativa. El Modelo tiene su base en la Misión, Visión y Valores de la UNAN-Managua, promueve la integración/ articulación institucional de los procesos de docencia e investigación de grado, postgrado y la extensión universitaria. El modelo promueve como sus principios fundamentales los enfoques "Antropocéntrico y Sistémico de los Métodos de Investigación". El modelo representa un proceso continuo e interactivo de investigación, innovación y emprendimiento, en el que la investigación se retroalimenta de los hallazgos relevantes que surgen de los procesos de innovación y emprendimiento.

Quiero destacar en esta obra el Enfoque Antropocéntrico, que privilegia la atención a los estudiantes y servir mejor a la gente. Promueve fortalecimiento de: a) El espíritu de colaboración en cada uno de los miembros de la comunidad universitaria, (b) implementar una comunicación efectiva entre todos y todas, (c) desarrollar una gestión institucional más horizontal y por lo tanto menos burocrática y más eficiente; y (d) aplicar en el día a día un espíritu de servicio, hacia la comunidad universitaria en particular y la sociedad nicaragüense en general.

Así mismo el Enfoque Sistémico implica que los procesos de investigación, deben de entenderse y gerenciarse como un sistema complejo, multidimensional, que requiere un determinado equilibrio (Oferentes y Demandantes) del mercado de factores tecnológico y del mercado destino 
(consumidor). Este sistema, básicamente consiste en un subsistema de entrada, (proveedores), varios subsistemas de procesamientos integrados entre sí (de valor agregado, de mercado, estadísticos, económicos, geográfios, etc.) y un subsistema de salida (transformación del conocimiento en tecnología disponible), enfatizando en la devolución de resultados hacia los usuarios (estudiantes, productores (as), sector público, sector privado, etc.)

Con el modelo $\mathrm{I}+\mathrm{D}+\mathrm{i}$ de la UNAN-Managua se promueve la investigación orientada a la solución de problemas, se asumen los retos y desafíos de problemas actuales complejos, multi-causales, de efectos multidimensionales, identificados en el Plan Nacional de Desarrollo Humano (PNDH) impulsado por el Gobierno de Unidad y Reconciliación Nacional (GRUN) de Nicaragua.

En el Modelo $\mathrm{I}+\mathrm{D}+\mathrm{i}$ se definen tres grandes procesos:

(a) La Investigación en sus diferentes formas ésta se manifiesta como: investigación básica, estratégica, y aplicada. Y se muestra en la JUDC que año con año realiza nuestra universidad. También tenemos tres centros de Investigación: la Estación Experimental “El Limón”, el Centro de Investigación en Energía Renovable, y el Centro de Capacitación en Gestión Integral de Riesgos.

(b) La Innovación, en sus diferentes tipos: (a) Innovación organizacional e institucional, (b) Innovación de productos e (c) Innovación de Procesos. En este aspecto la FAREM-Estelí ya ha desarrollado 11 ediciones de la Jornada de Iniciativa Global de Innovación Aplicada (IIGA) con la Universidad Estatal de Grand Valley, ha participó en el Raleigh de Innovación 2014 promovido por CONICYT y la promoción de ferias tecnológicas, donde se destacan las carreras de ingeniería. Este año vamos a presentar nuestro quehacer en el I Foro de Innovación y emprendimiento.

(c) El Desarrollo Tecnológico, entendido este como el efecto más importante y el medio indispensable para alcanzar los impactos socio-económicos esperados tanto de la investigación como de la innovación. Ambos procesos, son comprendidos como el motor del desarrollo socioeconómico del país, los cuales correctamente articulados con los procesos de emprendimientos, constituyen el soporte necesario para el desarrollo humano sostenible de la sociedad nicaragüense en su conjunto. Hemos diseñado el Programa de Innovación de FAREM-Estelí que presentaremos el viernes ante el Consejo Universitario de UNAN-Managua.

El Modelo plantea tres salidas a esta producción científica:

(a) Las publicaciones científicas, expresadas en las tres modalidades básicas de la comunicación científica, tales son artículos científicos, ensayos y artículos científicos de revisión. Nuestra facultad tiene hoy 1 Revista Científica; la Revista Multiensayos, la Webapp de Gestión de la Investigación (GInvest), presencia en redes sociales.

(b) Los resultados del proceso de innovación, los que incluyen el registro de patentes, propiedad intelectual y marcas. 


\section{(c) Las iniciativas del proceso de emprendimiento.}

Sin embargo, para la UNAN-Managua la implementación de este Modelo $\mathrm{I}+\mathrm{D}+\mathrm{i}$ demanda una actitud profesional de identidad, compromiso y pertenencia, de mayor responsabilidad en el trabajo diario, de actitud creativa, de esfuerzos, de perseverancia, de lucha y sacrifico para resolver efectivamente los problemas del país. De esta manera, se pueden demostrar los efectos positivos del desbordamiento tecnológico, desde la universidad hacia la sociedad, para visibilizar los impactos positivos de los resultados de la investigación científica, y contribuir desde la universidad al desarrollo humano sostenible de la sociedad nicaragüense en su conjunto.

El libro que hoy estamos presentando es una herramienta de trabajo que debe ser aprovechada por investigadores e investigadoras, estudiantes, tomadores de decisiones y pueblo en general; para que desde su quehacer cotidiano impulsen de manera dinámica y comprometida los procesos de investigación e innovación en nuestro país. El Dr. Pedroza está dando su aporte y nuestro reto es aprovecharlo y mejorarlo. 